\title{
Electromotive administration of topical medications in clinical physiotherapy practice: A review
}

\author{
Odeyemi Emmanuel*, Oyedemi Jerremiah, Okonji Adaobi \\ Department of Medical Rehabilitation, College of Health Sciences, Obafemi Awolowo University, Ile-Ife, Osun State, Nigeria
}

Email address:

odeyemiemmanuel@yahoo.com (O.Emmanuel)

\section{To cite this article:}

Odeyemi Emmanuel, Oyedemi Jerremiah, Okonji Adaobi. Electromotive Administration of Topical Medications in Clinical Physiotherapy Practice: A Review. American Journal of Health Research. Special Issue: Supplementary Prescribing in Nigeria: A Needy Concept to Promote Clinical Physiotherapy Practice. Vol. 2, No. 5-1, 2014, pp. 34-39. doi: 10.11648/j.ajhr.s.2014020501.17

\begin{abstract}
Oral and injection routes of drug administration has adverse effect in the body system, hence, there is paradigm shift in route of drug administration to the use of electromotive force via the skin where applicable; and this by passes the first pass effect metabolism. Both iontophoresis and ultra-sonophoresis are examples of procedures for the electromotive administration of drugs. Potential serious side-effects are eliminated because transdermal routes of drug administration are known to possess little or no side effects. Iontophoresis is the introduction of medicinal ions into the body using Direct Current It is a painless, sterile and non invasive technique with minimal adverse reactions in the gastro-intestinal system. The dose depends on current and time of treatment and a typical dosage is $40 \mathrm{~mA}-\mathrm{min}$. This review revealed that Iontophoresis is being used to subdue inflammation using topical Non-steroidal anti-inflammatory drugs, administer antibiotics to combat infection, manage bicep brachii spasticity of stroke survivours, promote wound healing, reduce bacteria colonization, combat fungal infection; and has produced analgesic effects in several studies. Also, the reviewed showed that ultrasonophoresis is relevant in clinical physiotherapy practice.
\end{abstract}

Keywords: Iontophoresis, Clinical Practice, Electromotive Drug Administration, Ionic Charge

\section{Introduction}

\subsection{Iontophoresis}

There are emerging roles for physiotherapists in drugs prescription and administration with evidence based guidelines being established towards the establishment of requisite trainings and legislations to support practice $[1,2]$. Drug therapy is usually required for orthopaedic/musculoskeletal disorders and it is primary used to reduce pain and inflammation. Physiotherapists are currently re- focusing on alternate route of drug therapy such as transdermal administration [3]. This scope of practice is increasingly expanding, as physiotherapists continue to identify with new roles. However, a primary concern would be employing the most effective route of drug administration within the scope of physiotherapy practice and disease condition

The bioavailability of drugs is an essential concept in drug administration. It is the measurement of the rate and extent to which an unchanged fraction of an administration dose reaches the systemic circulation [4]. Bioavailability of certain drugs is adversely affected by certain factors such as presystemic metabolism [4]. Oral routes of drug administration are known to be significantly affected by the first pass effect metabolism, with the intravenous route known to have a $100 \%$ bioavailability [4]. However, with the limitations involved in the IV routes and injection routes, other routes less affected by first pass and known for other adverse effects are being explored for their obvious advantages $[5,6]$

In order to increase the efficacy of certain drugs, more especially those needed for local actions as common with many 'physiotherapeutic' drugs are currently been emphasized [7]. The transdermal route of drug administration has been an age long means of delivery therapeutic substances to the body especially for local effects [8]. It involves the use of direct manual and transdermal patch applications, and more recently Electromotive Drug Administration $[3,9,10]$. In pharmacotherapy, increasing study are being focused on the use of therapeutic medications randomly as adjuncts within the domains of physiotherapy treatments $[[11,12,13,14]$. Iontophoresis is regarded as a 
form of Electromotive Drug Administration (EMDA), and it is a technique that uses a small electric charge to deliver drugs and bioactive agents via the skin $[3,9,11,13,15]$. It was simply defined as the application of an electrical potential that maintains a constant electric current across the skin and enhances the delivery of ionized as well as unionized moieties [16].There are enhanced strategies to deliver medications through the skin especially drugs of differing lipophilicity and molecular weight $[9,17]$. Potential serious side-effects are eliminated because transdermal routes of drug administration is known to possess little or no side effects $[12,18,19]$. The most challenging for physiotherapist is understanding the knowledge of active ingredient in topical medications $[3,20]$. Marowino provided a cross reference for charges on some drugs [21], (Table 1).

\subsection{Historical Background}

The history of iontophoresis is reported in literature as far back as the mid 1700s [22]. The method of iontophoresis was described by Pivati in 1447; and Gavani and Vota. The two scientists in the $18^{\text {th }}$ century used the knowledge of electricity that it can move different metal ions, and that the movement of the ions produce electricity [22]. According to Helmstadter, increasing progress was made in the $19^{\text {th }}$ century notably by William James Morton (1846-1920), Stephen Leduc (18531939) and Fritz Frankenhauser (1868) on electromotive administration of metal ions and alkaloids [23]. At $20^{\text {th }}$ century, the method of administering pharmacological agents by iontophoresis became popular due to the work of Leduc (1900) who introduced the term 'iontotherapy' and formulated the laws for this process [24]. Until the early $20^{\text {th }}$ century, current medicated drug delivery was known as "cataphoresis". Frankenhauser introduced the term "iontophoresis" before 1908 [22]. Iontophoresis is the introduction of ionic molecules into the skin by means of electricity [25]. However, it has been noted that due to improvement in understanding its mechanism, many nonionic materials such as polypeptides are been speculated to be delivered into the body by iontophoresis.

Table 1. Ionic charges of selected drugs and relevant conditions [21]

\begin{tabular}{lll}
\hline Drugs & Charges & Conditions \\
\hline Acetic acid & Negative & Calcium deposits \\
Chloride & Negative & Scar tissue \\
Dexamethasone & Negative & Inflammation- tendonitis/ bursitis \\
Calcium & Positive & Muscle spasm/muscle dysfunction \\
Hydrocortisone & Positive & Anti- inflammatory steroid/myositis \\
Zince oxide & Positive & Antiseptic/wound healing \\
Salicylates & Negative & Arthralgia/myalgia \\
Lidocaine & Positive & Tenosynovitis \\
Atropine sulphate & Positive & Hyperhydrosis \\
Magnesium & Positive & Muscle relaxant \\
Zinc oxide & Positive & Wound healing/antiseptic \\
\hline
\end{tabular}

The following have been identified as the benefits of iontophoretic techniques of both ionized and un-ionized drugs:

- Depending on the current applied, it enables continuous or pulsatile delivery of drug.
- Permits easier termination of drug delivery.

- Offers better control over the amount of drug delivered since the amount of compound delivered depends on applied current, duration of applied current, and area of skin exposed to the current.

- Restoration of the skin barrier functions without producing severe skin irritation.

- Improving the delivery of polar molecules as well as high molecular weight compounds.

- Ability to be used for systemic delivery or local (topical) delivery of drugs.

- Reducing considerably inter and or intra subject variability in view of the fact that the rate of drug delivery is more dependent on applied current than on stratum corneum characteristics.

- Improved drug delivery over passive transdermal delivery method

- It avoids GIT side effect, inactivation of drug by GIT enzymes, interaction of drug with food and first-pass metabolism of drugs in GIT.

- It provides controlled and sustained release of the medicament.

- It improves the bioavailability of drug.

- It provides uniform drug plasma concentration.

- It improves the patient's compliance.

- It can be administered to non- responsive, unconscious and nauseating patient.

- It also provides easy termination of drug in case of toxicity by removal of the formulation from the skin [26, 27, 28, 29$]$.

\subsection{Mechanism, Dosage and Application}

The mechanism of iontophoresis is based on the general principle that like charges repel. Thus, during iontophoresis, if delivery of a positively charged drug (DC) is desired, the charged drug is dissolved in the electrolyte surrounding the electrode of similar polarity, i.e. the anode. On application of an electromotive force the drug is repelled and moved across the stratum corneum towards the cathode, which is placed elsewhere on the body [30]. According to Glikfeld, the movement of the drug ions between the electrodes occurs through the skin and not on the surface. Thus communication between the electrodes along the surface of the skin has been shown to be negligible [26].

Although, Direct or Galvanic current is the most suitable for iontophoretic delivery of drugs but there are newer evidences supporting alternate and faradic currents. The dose period depends on the current and time of treatment. It is expressed as milliampere minutes (mA-min) with the recommended milliampere-minute dose depending on the electrode used. [21]) a typical dosage is $40 \mathrm{~mA}$ - (e.g., $4 \mathrm{~mA}$ $\mathrm{x} 10$ minutes or $2 \mathrm{~mA}$ x 20 minutes, etc). The current setting is chosen based on patient comfort and when using mobile patches, a microampere current is used for much longer periods of time. [21].

Medical device manufacturers now provide automated and portable devices which are being developed to reduce the 
time burden of iontophoresis treatment for patients. There is the introduction of a more mobile solution to iontophoresis treatment - sold under the brand name of IontoPatch ${ }^{\circledR}$ - that may be worn by the patient for a 24 -hour period. The clinical time component of treatment is eliminated altogether and the patient gets a more sustained 24 hour effect [31].

Iontophoresis is effective in many clinical conditions, while it is been considered investigational in certain areas. [9, $11,23,32]$. The use of the application in physical therapy had been well documented by Costello and Jeskey [11]. Most of these reports are, however, poorly substantiated or are reports of clinical trials that lacked controls. Further studies with larger sample sizes have also been recommended [3].

Drugs such as analgesics, muscle relaxants and antiarthritis are in the domain of drugs with differing lipophilicity and molecular weight [17]. In an attempt to minimize and or avoid the side effects; mild, moderate or adverse, of these drugs in the systemic circulation; there is increasing focus on local drug delivery directly to site of action. There are other global issues such as non-compliance with the use of oral medications as a result of certain factors such as taste, bulk etc that are being put into consideration. [4, 33]. Iontophoresis has been reported to be effective in the treatment of hyperhidrosis and several musculoskeletal conditions using appropriate medications. [3,9,14, 34].

\subsection{Non-Steroidal Antiflammatory Drugs (NSAIDs)}

Iontophoresis has also been documented to subdue inflammation [21]. The oral administration of Non-steroidal anti-inflammatory drugs provokes adverse effects most especially in the gastrointestinal tract [4]. NSAIDS are well known pharmacologic agents that produce analgesic, antipyretic and anti-inflammatory effects [4, 35]. Hence, increasing interest has been shown in studies establishing the efficacy of NSAIDs administration via other routes [12, 14]. Diclofenac, Ibruprofen, piroxicam, Pirprofen, Lys-aspirina, Ketorolac, salicylic acid have all been reportedly used for investigational studies for their therapeutic effects most especially in musculokskeletal conditons and sport related injuries $[14,36]$. Diclofenac and Ibruprofen were reportedly used to provide topical analgesia using iontophoresis [28, 37].

\subsection{Magnesium and Gentamicin Sulphate}

Onigbinde et al showed that magnesium sulphate iontophoresis was able to reduce bicep brachii spasticity among stroke survivors. Gentamicin sulphate iontophoresis was also reported by Onigbinde et al to promote wound healing and reduce bacteria colonization [3]. Iontophoresis of antibiotics has been shown to be more effective for treating superficial infections than systemically administered antibiotics.

\subsection{Corticosteroids}

Corticosteroids such as dexamethasone sodium phosphate (or dexamethasone in a sodium phosphate solution) and methylprednisolone sodium succinate have been widely reported for the treatment of pain and inflammatory conditions such as tendinopathies and arthritis [14, 38].

\subsection{Lidocaine}

Lidocaine iontophoresis has also been explored and increasingly considered for pain management in soft tissue injuries [38, 39, 40]. Prospective studies such as the iontophoresis of lidocaine for the pain management of acute soft tissue injuries in the emergency had been found to be more effective than the oral administration of non-steroidal anti-inflammatory medication [38]. Similarly, patients with 'tennis elbow', showed clinical improvement when iontophoresis of lidocaine was administered [39]. Other studies have likewise established these prospects while further studies are being suggested to substantiate the use of lidocaine iontophoresis $[12,14]$.

\subsection{Glucosamine}

Glucosamine Sulphate iontophoresis has been documented in several studies to be effective in alleviatory pain and improving functions among subjects with knee OA [13].

\subsection{Copper}

A $0.2 \%$ solution of copper sulphate iontophoresis has been used to treat chronic fungal infections of the feet following an average of six to seven treatments [42].

\subsection{Lithium}

Lithium iontophoresis was reportedly used to obtain therapeutic effect in the treatment of gout [43].

\subsection{Acetic Acid}

Acetic acid iontophoresis combined with taping, gave considerable relief from pain and stiffness symptoms in the management of Plantar Fascitis [44]. Acetic acid iontophoresis has been described in case reports for the treatment of patients with calcium deposits around the shoulder and for myositis ossificans affecting the quadriceps femoris muscle. There were reported resolution of the calcium deposition, with reduction in symptoms and improved function in the two cases. Iontophoresis has also been indicated for the following purpose; useful in treating scars or adhesions, to treat inflammatory conditions of the skin and joints, spasm relief, analgesia, to treat edema, and for treating open skin lesion [45].

Iontophoresis has also been documented for dermatological conditions such as psoriasis, inflammatory skin conditions, decubitus ulcer and burns. There is likewise a similar increasing interest in the other health field such as dentistry, surgery etc [11]. According to Costello and Jeske, the interests of the pharmaceutical and physical therapy professions in iontophoresis are often different [11]. Many medical practitioners are interested primarily in the delivery of medication to achieve a systemic concentration sufficient for a desired effect whereas physical therapists are interested 
in directing larger quantities of a medication into a localized treatment region and minimizing systemic levels of the medication [11].

\subsection{Contraindications and Adverse Effect}

Typical of drug therapies, there are possible contraindications and adverse effects. Amongst are electric and chemical burns, pain arising from high current density, ionic competition and cardiac arrest.

\section{Ultrasonophoresis}

The stratum corneum, poses a formidable barrier to drug penetration thereby limiting topical and transdermal bioavailability of drugs [46]. Transdermal drug delivery has gained prominence over other forms of drug delivery due to its potential advantages, including minimal trauma induction, noninvasiveness, increased patient compliance and potential for continuous, controlled delivery [47]. Drug of high molecular weight, ionic and polar which can only be deliver into the deeper layer of the skin by various skin penetration that requires chemical enhancers, drug formulation enhancer and physical enhancer which includes iontophoresis, sonophoresis (phonophoresis) and electroporation to overcome this formidable barrier [48].

There are several methods of delivering medication transcutaneously but the most common is through intramuscular injection which is generally considered to be invasive [49]. The recent advances in non-invasive penetration enhancer can be categorized into three generations of development. Archana described the firstgeneration transdermal delivery systems or enhancer in clinical use for delivery of small, lipophilic, low-dose drugs which are drugs that can cross the skin at therapeutic rates with little or no enhancement. [50]. This delivery systems is limited primarily by the barrier posed by skin's outermost layer called stratum corneum [51]. Second-generation delivery systems use chemical enhancers, iontophoresis and non-cavitational ultrasound that involve mechanical force that is referred to as phonophoresis. They yielded additional advances for small molecule delivery by increasing skin permeability and driving forces for transdermal transport [49]. Third- generation delivery systems target their effects to skin's barrier layer of stratum corneum using microneedles, thermal ablation, microdermabrasion, electroporation and cavitational ultrasound [51].

Ultrasound (US), a form of acoustic energy, is often used in physical therapy because of its non-thermal mechanisms which play a primary role in producing a therapeutically significant increase in the rate of cell membrane permeability and molecular diffusion [52]. Use of ultrasound in therapeutics and drug delivery has gained importance in recent years, evident by the increase in patents filed and new commercial devices launched [53]. Therapeutic ultrasound is a commonly used modality that utilizes high-frequency sound waves (usually 1 to $3 \mathrm{MHz}$ ) that pass through the skin to underlying structures. The tissue temperature is raised with increased blood flow to skin, it decreases pain secondarily by decreasing muscle spasm, and promote healing of various tissue. Other claims, however, such as the utility of ultrasound as anti-inflammatory modality, remain controversial [54]. Phonophoresis also known as ultrasonophoresis is an example of these ultrasoundenhanced therapies described as the migration of drug molecules through the skin under the US transducer. The technique uses therapeutic ultrasound to introduce pharmacologic agents, usually anti-inflammatory or analgesic drugs, through intact skin into the subcutaneous tissues [55]. Furthermore, phonophoresis has been shown to increase skin permeability to various low and high molecular weight drugs, including insulin and heparin [53].

In physical therapy, phonophoresis of nonsteroidal antiinflammatory drugs (NSAIDs) is commonly used to treat inflamed tissues, and in addition phonophoresis of ketoprofen allows the attainment of higher local concentration; whereas systemic exposure was lower [52]. Most authors have shown that, when compared with placebo treatments or ultrasound alone, phonophoresis provides clinical improvement by decreasing pain and increasing function [55]. In a randomized controlled study by Gurney et al to describe if phonophoresis will facilitate the transmission of HA in human connective tissue among 21 patients undergoing anterior cruciate ligament reconstruction surgery. They found that phonophoresis does not appear to facilitate the absorption of HA in connective tissue when compared with simple absorption (sham), [54]. Also, Giovana et al studied the effect of diclonfenac phonophoresis on human subject among 14 volunteers. They found that previously applied therapeutic ultrasound irradiation enhances the percutaneous penetration of the topical diclofenac gel [56]. Similarly, Saliba et al determined the effect of ultrasound on the transcutaneous absorption of dexamethasone using 2 grams of $0.33 \%$ dexamethasone cream with an intensity of 1.0 $\mathrm{W} / \mathrm{cm} 2(50 \%$ pulsed) at an output frequency of $3 \mathrm{MHz}$ for 5 minutes and compared with sham ultrasound treatments that were delivered at an intensity of $0.0 \mathrm{~W} / \mathrm{cm} 2(50 \%$ pulsed $)$ at an output frequency of $3 \mathrm{MHz}$ for 5 minutes [55]. They observed that the rate of appearance and the total concentration of dexamethasone in the serum were greater in subjects after phonophoresis than after sham ultrasound. The sham group had only trace amounts of dexamethasone in the serum, indicating that drug absorption was negligible without the ultrasound energy [55].

\section{Conclusion}

This review revealed that iontophoresis and ultrasonophoresis are effective and well tolerated methods for delivering ionized medications, bio-active agents and drug molecules through the dermis using minimal electric current and ultrasound. Also, the review showed the spotential prospect of iontophoresis and phonophoresis as electromotive means of administering drugs. 


\section{References}

[1] WCPT (2013). http://www.wcpt.org/node /101751 Accessed July 14, 2014

[2] CSP UK (2013).http://www.csp.org.uk/ professionalunion/professionalism/ prescribing Accessed July 14, 2014

[3] Onigbinde Ayodele Teslim, Olaogun M.O.B, Obembe Adebimpe Olayinka, Samotu Adedayo Ayobami, Bamitale Kayode D.S, Ogundele Abiola, Adetoogun Gbadegesin Elubode (2013). Electromotive drug administration of magnesium sulphate on spastic biceps brachii of stroke survivors: A Technical report. Online Journal of Medicine and Medical Science Research, Vol 2, 4, 38 - 43.

[4] Dale, M.M., Rang, H.P., \& Dale M. M. (2007): Rang \& Dale's Pharmacology. Edinburgh: Churchill Livingstone.

[5] Saggini, R.; Zoppi, M.; Vecchiet, F.; Gatteschi, L.; Obletter, G.; Giamberardino, M. A (1996). Comparison of electromotive drug administration with ketorolac or with placebo in patients with pain from rheumatic disease: a double-masked study. Clin Ther, 18(6), 1169-1174.

[6] Vranken, J. H.; Dijkgraaf, M. G. W.; Kruis, M. R.; van Dasselaar, N. T.; van der Vegt, M. H. (2005)Iontophoretic administration of $\mathrm{S}(+)$ - Katamine in patients with intractable central pain: A placebo-controlled trial. Pain, , 118, 224-231

[7] Drugs.com Physiotherapeutic: (2014): $\mathrm{http} / /$ :www.drugs.com/dict/ physiotherapeutic. html. Accessed July 14, 2014

[8] Costello CT, Jeske AH, (1995). Iontophoresis: Applications in transdermal medication delivery. Physical Therapy Journal; (75): 554-563.

[9] Capital Blue (2014) Medical Policy; Policy Title: Iontophoresis/ Phonophoresis: Policy Number Mp-4.013 Original Issue Date (Created): July 12, 2002; Most Recent Review Date (Revised): November 26, 2013; Effective,

[10] Kalia, Y.N., et al. ( 2004) Iontophoretic drug delivery. Adv Drug Deliv Rev. 56(5): p. 619-58.

[11] Costello CT, Jeske AH. Iontophoresis: Applications in transdermal medication delivery. Physical Therapy Journal, 1995; (75): 554-563.

[12] Hamann H, Hodges M, Evans B, (2006): Effectiveness of iontophoresis of anti-inflammatory medications in the treatment of common musculoskeletal inflammatory condition: a systematic review. Physical Therapy Reviews, 01 Sepetmber, 11/3(190-194).

[13] Onigbinde AT, Adetogun GE, Ojoawo AO, Omotuyi OC. ( 2009) Comparative efficacy of low metal glucosamine sulphate iontophoresis in the management of lumbar spondylosis. Ind J Phys Occup Ther; 3(3): 12-15.

[14] Clijsen R, Taeymans J, J.P. Baeyens, A.O. Barel and P. Clarys (2012) The Effects of Iontophoresis in the Treatment of Musculoskeletal Disorders - A Systematic Review and MetaAnalysis; Drug Delivery Letters, , 000-000 1.

[15] Panus PC, Cambell J, Kulkarni B. (1996) Effect of iontophoretic current and application time on the transdermal delivery of Ketoprofen in man. Pharm Scs,; 2: 467-469.
[16] Williams A.C, BarryB.W,(1992) Skin absorption enhancers, Crit. Rev. Ther. Drug. Carrier Syst.,1992;9:305-353.

[17] Aetna. (2013) Clinical Policy Bulletin: Iontophoresis. Number: 0229. http://www.aetna.com/cpb/medical/data/200_299 /0229.html, 2013. Accessed on 3rd January 2012.

[18] Ines, L.P. and J.A. da Silva, (2005) Soft tissue injections. Best Pract Res Clin Rheumatol, 19(3): p. 503-27.

[19] Banga A.K., Panus P.C. (1998): Clinical Application of Iontophoretic Devices in Rehabilitation Medicine. Critical Reviews in Physical and Rehabilitation Medicine, 10(2): p. 147-179.

[20] Onigbinde Ayodele Teslim, Orolade Ibidayo Akanji. An assessment of knowledge and opinion of Nigerian physiotherapists on application of Iontophoresis in the management of selected skin disorders and Arthritis. Technology and Health Care, 2012

[21] Marowino Tiziano (2014) Iontophoresis in Pain Management. Practical Pain Management. www. Practical Pain Management.com. Accessed on the $26^{\text {th }}$ August 2014.

[22] Khan A., Yasir M., Asif M., Chauhan I., Alok P. Singh, Rajat Sharma,Pradeep Singh and Shubham Rai (2011) Iontophoretic drug delivery: History and applications. Journal of Applied Pharmaceutical Science 01 (03); 2011: 11-24

[23] Helmstädter, A. (2001) The history of electrically-assisted transdermal drug delivery ("iontophoresis"). Pharmazie;56: 583-587.

[24] Green P.G, Flanagan M, Shroot B, Guy RH. (1993) In Physical Skin Penetration Enhancement, Walters, K.A.; Hadgraft. J. Eds.; Marcel Dekker Inc.: New York,

[25] Thomas CL, ed. Tubers Cyclopedic (1997) Medical Dictionary. 13th ed. Philadelphia, Pa: FA Davis Co; 19773-47.

[26] Glikfeld P., Cullander C., Hinz R.S., Guy R.H., (1988) A new system for in vitro studies of iontophoresis, Pharm. Res., 5: 443-446

[27] Williams A.C., B.W. Barry, Terpenes (1991) and the lipidprotein partitioning theory of skin penetration enhancement. Pharm. Res.,;8:17-24.

[28] Rijwan M, Aquil M, Talegoankar S, Azeem A, sultana Y, Ali A (2009) Enhanced transdermal drug delivery techniques: an extensive review on patents. Recent Patents on Drug Delivery and Formulation 3(2): 105-124

[29] Bijaya G, Preethi GB, Roopak M, Versha P. Transdermal delivery of ibuprofen and its products.

[30] Banga A.K., Panus P.C. (1998): Clinical Application of Iontophoretic Devices in Rehabilitation Medicine. Critical Reviews in Physical and Rehabilitation Medicine, 10 (2): p. 147-179by

[31] Practical Pain Management (2008): Iontophoresis in Pain Management, Published on Practical Pain Management. Assessed Online http://www.practical painmanagement.com/treatments/interventional/iontophoresispain-management

[32] Panchagnula R., O. Pillai, V.B.Nair, P.Ramarao. (2000): Transdermal Iontophoresis revisited. Current Opinion in Chemical Biology, 4:468-473. 
[33] Bilir A, Gulec S, Erkan A, Ozcelik A. (2007) Epidural magnesium reduces postoperative analgesic requirement. $\mathrm{Br} \mathrm{J}$ Anaesth, (98): 519-23.

[34] TEC Assessment (2000). Iontophoresis for medical indications. www.tecassessment. com.

[35] Brukner, P., Khan, K., (2007) Clinical sports medicine. 3dr ed., Sydney: McGraw-Hill. 1032.

[36] Sylvestre Jean-Philippe (2007): Applications Of Iontophoresis In Sports Medicine; A thesis submitted for the degree of Doctor of Philosophy.University of Bath; Department of Pharmacy and Pharmacology ; November 2007.

[37] Hariharan S, Ramsewak R, Chen D, Merritt-Charles L, Bridglal C. (2007).A study of the efficacy of diclofenac iontophoresis for providing effective topical analgesia. Internet Journal of Pain, Symptom Control and Palliative Care, 13 Auguust, Vol./Is. 5/2(0-10), 15288277.

[38] Bailey, D.C., et al.,( 2003) A Comparison of the Use of Iontophoresis and Oral Non-steroidal Anti-inflammatory Medication in the Pain Management of Acute Soft Tissue Injuries in the Emergency Department Setting. Acad Emerg Med,10 (5): p. 470

[39] Yarrobino, T.E., et al., (2006) Lidocaine iontophoresis mediates analgesia in lateral epicondylalgia treatment. Physiother Res Int,. 11(3): p. 152-60.

[40] Onigbinde A.T, Talabi A.E, Ogunsakin E.A, Adesoye A.A, Awotipe A Mbada C.E, Obiyemi O.O, Oyerinde O. (2010): Acute effect of lidocaine iontophoresis on pain and joint motions during application of mobilization techniques- A Technical Report. Ghana Journal of Physiotherapy Vol 2 No 1, $23-29$,

[41] Onigbinde Ayodele Teslim, Olafimihan Kehinde Foyeke, Ojoawo Adesola, Mothabeng Joyce, Ogundiran Opeyemi Olufemi (2011) Management of decubitus ulcer using Gentamycin sulphate iontophoresis- A case study. Internet journal of Allied Health Sciences and Practice, vol 9, 3, 1 - 4

[42] Haggard HW, Strauss MJ, Greenberg LA. (1939) Fungous infections of the hands and feet treated by iontophoresis of copper. JAMA.;112:1229-1232.

[43] Garzione Garzione J.E, (2008) Pain Management Special Interest Group. Lithium Iontophoresis for Gout Pain: a case study. Orthopaedic Physical Therapy Practise, 01 September, Vol./Is. 20/3(149-149).

[44] Osborne H.R., Allison GT, 2006: Treatment of plantar fasciitis by Low Dye taping and iontophoresis: Short term resuts of a double blinded, randomized, placebo controlled clinical trial of dexamethasone and acetic acid. British Journal of Sports Medicine, 01 June, Vol./Is. 40/6(545-549).

[45] Perron M, Malouin F (1997). Acetic acid iontophoresis and ultrasound for the treatment of calcifying tendinitis of the shoulder: a randomized control trial. Arch Phys Med Rehabil. 1997 Apr;78(4):379-84.
[46] Nikhil Sharma, GetaAgarwal, A. C. Rana, Zulfiqar Ali Bhat, Dinesh Kumar"A Review: Transdermal Drug Delivery System: A Tool For Novel Drug Delivery System",Int. J. Drug Dev. \& Res., Jul-Sep 2011, 3(3): 70-84

[47] Vijay Krishna Rachakonda (2008). Effective screening of chemical penetration enhancers for transdermaldrug delivery. Thesis Submitted to the Faculty of the Graduate College of the Oklahoma State University in partial fulfillment of the requirements for the Degree of Master of science.

[48] Dasgupta, Rajdeep; Banthia, Ajit Kumar; Tibarewala, D.N. Trends in Biomaterials and Artificial Organs Study of diffusion characteristics of salicylic acid through cellulose acetate membrane and extracted mouse skin by iontophoresis.

[49] Akinbo, Sunday; Owoeye, Oluwatoyosi; Adesegun, Sunday, Comparison of the therapeutic efficacy of diclofenac sodium and methyl salicylate phonophoresis in the management of knee osteoarthritis Turkish Journal of Rheumatology Jun 1, 2011

[50] Archana K. Gaikwad Aurangabad Reviewed Article Transdermal drug delivery system: Formulation aspects and evaluation 431001, Maharashtra India. Email:g29archana@ yahoo.com Accepted 7 February, 2013

[51] Mark R. Prausnitz and Robert Langer , Transdermal drug delivery, NIH Public Access available in PMC 2009 June 23.

[52] Hsieh Yueh-Ling. Hung-Kuang University, Taichung, 34, Chung-Chie Road, Sha Lu, Taichung 433, Taiwan, Republic of China Effects of Ultrasound and Diclofenac Phonophoresis on Inflammatory Pain Relief: Suppression of Inducible Nitric Oxide Synthase in Arthritic Rats The American Physical Therapy Association

[53] Kumar Sampath, Debjit Bhowmik, M.Komala. Indian Journal of Research in Pharmacy and Biotechnology Volume 1(3) May-June 2013 Page 379 Transdermal sonophoresis technique- an approach for controlled drug delivery. Department of Pharmaceutical Sciences, Coimbatore medical college, 2. Karpagam University, Coimbatore.

[54] Gurney A. Burke, Daniel Wascher, Robert Schenck, Alexandria Tennison, Bettina Jaramillo, DPT Sports Physical Therapy Absorption of Hydrocortisone Acetate in Human Connective Tissue Using Phonophoresis

[55] Saliba Susan, Dilaawar J. Mistry, David H. Perrin, Joe Gieck, Arthur Weltman (2007). Phonophoresis and the Absorption of Dexamethasone in the Presence of an Occlusive by the National Athletic Trainers Journal of Athletic Training 2007;42(3):349-354 .

[56] Giovana C. ROSIM, Cláudio Henrique Barbieri, Fernando Mauro Lanças, NiltonMazzer (2004). Diclofenac phonophoresis in human volunteers. Seminar at the department of Biomechanics, Medicine and Rehabilitation of the Locomotor Apparatus, RibeirãoPreto School of Medicine, São Paulo University, RibeirãoPreto (SP), Brazil and tDepartment of Analytic Chemistry, São Carlos Institute of Chemistry, São Paulo University, São Carlos (SP), Brazil; 